\title{
Handgrip strength and subclinical carotid atherosclerosis in relation to platelet levels among hypertensive elderly Japanese
}

\author{
Yuji Shimizu ${ }^{1,2}$, Shimpei Sato ${ }^{1}$, Jun Koyamatsu ${ }^{3}$, Hirotomo Yamanashi ${ }^{3}$ Mako \\ Nagayoshi ${ }^{1}$, Koichiro Kadota ${ }^{1}$, Shin-Ya Kawashiri ${ }^{1}$, Keita Inoue ${ }^{1}$, Yasuhiro Nagata ${ }^{4}$ \\ and Takahiro Maeda1,3 \\ 1 Department of Community Medicine, Nagasaki University Graduate School of Biomedical Sciences, Nagasaki, Japan \\ ${ }^{2}$ Department of Cardiovascular Disease Prevention, Osaka Center for Cancer and Cardiovascular Disease Prevention, Osaka, \\ Japan \\ ${ }^{3}$ Department of Island and Community Medicine, Nagasaki University Graduate School of Biomedical Sciences, Nagasaki, \\ Japan \\ ${ }^{4}$ Center for Comprehensive Community Care Education, Nagasaki University Graduate School of Biomedical Sciences, \\ Nagasaki, Japan \\ Correspondence to: Yuji Shimizu, email: shimizuyuji@nagasaki-u.ac.jp
}

Keywords: atherosclerosis, handgrip, hypertension, platelet, sarcopenia, Gerotarget

Received: June 21, $2017 \quad$ Accepted: August 16, $2017 \quad$ Published: September 01, 2017

Copyright: Shimizu et al. This is an open-access article distributed under the terms of the Creative Commons Attribution License 3.0 (CC BY 3.0), which permits unrestricted use, distribution, and reproduction in any medium, provided the original author and source are credited.

ABSTRACT

Age-related disruption of microvascular endothelium exacerbates hypertension and sarcopenia; and atherosclerosis is a well-known biological response to vascular endothelial injury. Therefore, prevalence of atherosclerosis among hypertensive elderly subjects may partly indicate the presence of an appropriate response to endothelial injury. We conducted a cross-sectional study of $\mathbf{7 9 5}$ elderly hypertensive Japanese subjects aged 60-89 years. Since platelet level is an indicator of vascular repair activity, subjects were stratified by platelet counts. No significant association between handgrip strength and subclinical carotid atherosclerosis (carotid intimamedia thickness (CIMT) $\geq 1.1 \mathrm{~mm}$ ) was observed for subjects with lower platelet counts, while a significant positive association was observed for subjects with higher platelets. Adjusted odds and $95 \%$ confidence intervals of subclinical carotid atherosclerosis for 1 standard deviation increments in handgrip strength were 0.86 $(0.61,1.22)$ for subjects with lower platelets and $1.82(1.26,2.64)$ for subjects with higher platelets. A positive association between handgrip strength and subclinical carotid atherosclerosis exists in hypertensive elderly subjects with higher, but not lower, platelet counts. These results lead us to speculate that subjects with a beneficial influence on prevention of sarcopenia (maintenance of handgrip strength) may possess the capacity of active endothelial repair that causes atherosclerosis.

\section{INTRODUCTION}

Hypertension and sarcopenia are known as agerelated diseases, and such diseases are reported to be exacerbated by disruption of the micro-vascular endothelium and impairment of blood flow via an increase in age-related inflammatory agents [1].

Endothelial dysfunction has been recognized as one of the initial mechanisms leading to atherosclerosis (increased arterial stiffness) [2]. Therefore, age-related diseases also may cause atherosclerosis. A longitudinal study of 195 older men during follow-up reported that atherosclerosis, as measured by carotid intima-media thickness (CIMT), is related to lower handgrip strength [3].

On the other hand, recent studies have reported an association between bone metabolism and vascular homeostasis [4-11] in view of the fact that hematopoietic stem cells (immature cells such as CD34-postive cells) derived from the bone marrow play a major role in vascular homeostasis [5-7]. Additionally, platelets play 
an important role in vascular culture together with CD34positive cells [12-21], and also induce the differentiation of human CD34-positive cells into foam cells [20], which are a well-known contributing factor in the development of atherosclerotic lesions. In fact, CD34-positive cells have previously been observed in atherosclerotic lesions in humans [22, 23]. And platelet-derived angiogenesis regulators promote angiogenesis during wound healing, tumor growth, and response to ischemia [24], while platelet-rich plasma also promotes angiogenesis [25].

In addition, active hematopoietic bone marrow declines with age [26-29], which could result in the agerelated decline of vascular homeostasis activity (including the increased capacity for developing atherosclerosis). Therefore, the presence of atherosclerosis among elderly hypertensive subjects may partly indicate the presence of active repair against disrupted micro-vascular endothelium and impaired blood flow. Since handgrip strength is an efficient tool to evaluate the loss of skeletal muscle mass and function due to its use as a predictor of old age disability [30], among elderly hypertensive subjects, those who can maintain handgrip strength with a beneficial influence on preventing sarcopenia may possess a higher capacity for developing atherosclerosis.

To clarify these associations, we conducted a crosssectional study of 795 elderly Japanese subjects aged 6089 years who underwent an annual health check-up from 2015-2016.

\section{RESULTS}

Among the total study population, 394 subjects had lower platelet values (platelets $<21.6 \times 10^{4} / \mu \mathrm{L}$ for men and $<22.6 \times 10^{4} / \mu \mathrm{L}$ for women) and $401 \mathrm{had}$ higher values (platelets $21.6 \times 10^{4} / \mu \mathrm{L} \leq$ for men and $22.6 \times 10^{4} / \mu \mathrm{L} \leq$ for women).

Table 1 shows platelet level specific characteristics of the present study population based on handgrip strength tertiles. Subjects with lower platelets demonstrated an inverse association between handgrip strength and age, mean CIMT, and a positive association with diastolic blood pressure, while subjects with higher platelet counts showed an inverse association between handgrip strength and age and a positive association with diastolic blood pressure, current smoker status and triglycerides.

Table 2 shows ORs and 95\% CIs for carotid

\section{Hypertension}
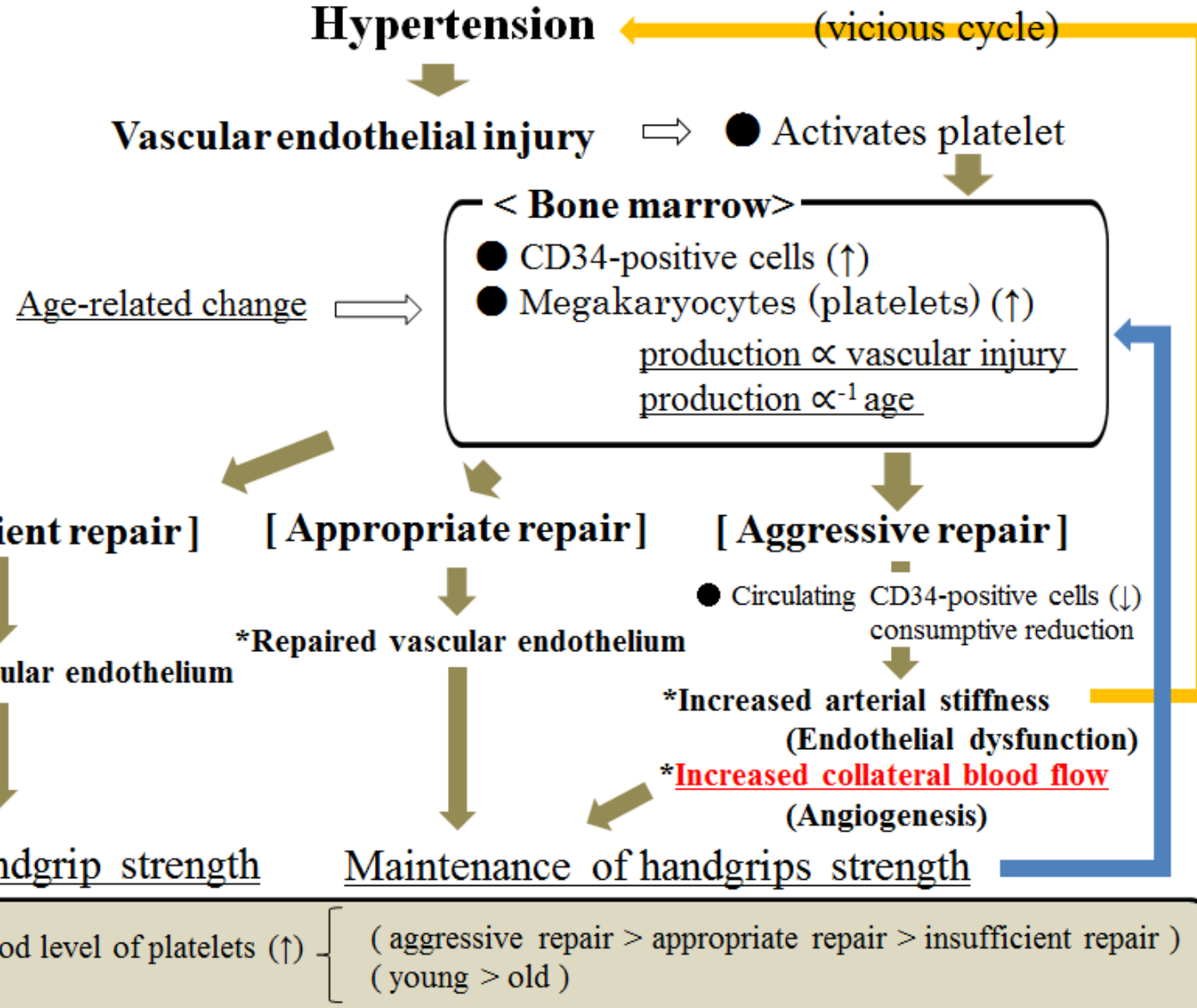

Figure 1: Possible mechanism underlying the association between handgrip strength and endothelium repair among hypertensive subjects. 
Table 1: Platelets level-specific characteristics of study population by handgrip strength level tertiles

\begin{tabular}{lcccc}
\hline & \multicolumn{3}{c}{ Handgrip strength tertiles } & \\
\cline { 2 - 4 } & T1 (low) & T2 & T3 (high) & p \\
\hline Lower platelets count & 123 & 142 & 129 & \\
No. at risk & $77.1 \pm 7.3$ & $74.0 \pm 6.5$ & $69.4 \pm 5.8$ & $<0.001$ \\
Age, years & 59.3 & 54.9 & 57.4 & 0.768 \\
Male, \% & $152 \pm 12$ & $154 \pm 14$ & $151 \pm 11$ & 0.071 \\
Systolic blood pressure, mmHg & $84 \pm 10$ & $87 \pm 11$ & $91 \pm 9$ & $<0.001$ \\
Diastolic blood pressure, mmHg & $23.8 \pm 3.7$ & $23.8 \pm 3.3$ & $23.9 \pm 3.1$ & 0.932 \\
Body mass index, kg/m ${ }^{2}$ & 58.5 & 52.8 & 53.5 & 0.606 \\
Current drinker, \% & 1.6 & 6.3 & 7.0 & 0.107 \\
Current smoker, \% & $96 \pm 47$ & $101 \pm 50$ & $103 \pm 62$ & 0.591 \\
Serum triglycerides (TG), mg/dL & $59 \pm 15$ & $57 \pm 15$ & $61 \pm 17$ & 0.222 \\
Serum HDL-cholesterol (HDL), mg/dL & $5.7 \pm 0.6$ & $5.6 \pm 0.4$ & $5.6 \pm 0.6$ & 0.358 \\
Serum HbA1c, \% & & & & \\
Mean carotid intima-media thickness & $0.75 \pm 0.15$ & $0.73 \pm 0.14$ & $0.69 \pm 0.12$ & $<0.001$
\end{tabular}

Higher platelets count

No. at risk

149

124

128

Age, years

$76.1 \pm 7.4$

$73.1 \pm 6.8$

$68.2 \pm 5.9$

$<0.001$

Male, $\%$

Systolic blood pressure, $\mathrm{mmHg}$

56.4

$$
55.6
$$

57.0

0.976

$153 \pm 12$

$152 \pm 13$

$151 \pm 14$

0.387

Diastolic blood pressure, $\mathrm{mmHg}$

Body mass index, $\mathrm{kg} / \mathrm{m}^{2}$

Current drinker, \%

$$
84 \pm 10
$$

$86 \pm 10$

$91 \pm 9$

$<0.001$

$23.4 \pm 3.0$

$$
23.3 \pm 2.9
$$

$24.1 \pm 2.8$

0.053

57.0

47.6

50.1

0.136

Current smoker, \%

0.0

0.8

18.0

$<0.001$

Serum triglycerides (TG), mg/dL

$115 \pm 57$

$112 \pm 57$

$136 \pm 102$

0.022

Serum HDL-cholesterol (HDL), mg/dL

$60 \pm 15$

$58 \pm 16$

$59 \pm 16$

0.789

Serum HbA1c, \%

$5.7 \pm 0.4$

$5.9 \pm 0.7$

$5.7 \pm 0.5$

0.015

Mean carotid intima-media thickness

(CIMT), mm

$0.72 \pm 0.15 \quad 0.73 \pm 0.16 \quad 0.71 \pm 0.13 \quad 0.479$

Handgrip strength levels tertiles: $<25.5 \mathrm{~kg}, 25.5-35.0 \mathrm{~kg}$, and $>35.0 \mathrm{~kg}$ for men and $<18.5 \mathrm{~kg}, 18.5-22.0 \mathrm{~kg}$, and $>22.0 \mathrm{~kg}$ for women. Lower platelets are defined as $<21.6 \times 10^{4} / \mu \mathrm{L}$ for men and $<22.6 \times 10^{4} / \mu \mathrm{L}$ for women.

atherosclerosis in total subjects, stratified by platelet levels. No significant association between handgrip strength and carotid atherosclerosis was seen in subjects with lower platelet levels, whereas a significant positive association was observed for subjects with higher platelet levels. The multivariable ORs and 95\% CIs of carotid atherosclerosis for $1 \mathrm{SD}$ increments in handgrip strength
(9.4 kg for men and $5.0 \mathrm{~kg}$ for women) were $0.86(0.61$, 1.22) for subjects with lower platelets and 1.82 (1.26,

2.64) for subjects with higher platelets.

An investigation into the effects of the association between handgrip strength and the two platelet level categories (high and low) on carotid atherosclerosis revealed a significant interaction; $p$ values for the effect 
Table 2: Odds ratios (OR) and 95\% confidence intervals (CI) for carotid atherosclerosis

\begin{tabular}{|c|c|c|c|c|c|}
\hline & \multicolumn{3}{|c|}{ Handgrip strength tertiles } & \multirow[b]{2}{*}{$p$ for trend } & \multirow{2}{*}{$\begin{array}{c}1 \text { SD increment } \\
\text { in handgrips } \\
\text { strength }\end{array}$} \\
\hline & T1 (low) & $\mathbf{T} 2$ & T3 (high) & & \\
\hline \multicolumn{6}{|l|}{ Total subjects } \\
\hline No. at risk & 272 & 266 & 257 & & \\
\hline No. of cases (percentage) & $44(16.2)$ & $45(16.9)$ & $37(14.4)$ & & \\
\hline Sex-and age-adjusted OR & 1.00 & $1.32(0.82,2.11)$ & $1.52(0.89,2.63)$ & 0.117 & $1.20(0.96,1.50)$ \\
\hline Multivariable OR & 1.00 & $1.32(0.81,2.16)$ & $1.58(0.89,2.80)$ & 0.111 & $1.23(0.97,1.56)$ \\
\hline \multicolumn{6}{|l|}{ Lower platelets count } \\
\hline No. at risk & 123 & 142 & 129 & & \\
\hline No. of cases (percentage) & $29(23.6)$ & $20(14.1)$ & $15(11.6)$ & & \\
\hline Sex-and age-adjusted OR & 1.00 & $0.63(0.33,1.20)$ & $0.65(0.30,1.38)$ & 0.208 & $0.78(0.56,1.08)$ \\
\hline Multivariable OR & 1.00 & $0.75(0.38,1.50)$ & $0.78(0.35,1.74)$ & 0.505 & $0.86(0.61,1.22)$ \\
\hline \multicolumn{6}{|l|}{ Higher platelets count } \\
\hline No. at risk & 149 & 124 & 128 & & \\
\hline No. of cases (percentage) & $15(10.1)$ & $25(20.2)$ & $22(17.2)$ & & \\
\hline Sex-and age-adjusted OR & 1.00 & $3.10(1.50,6.41)$ & $4.00(1.76,9.10)$ & $<0.001$ & $1.80(1.29,2.51)$ \\
\hline Multivariable OR & 1.00 & $2.82(1.30,6.11)$ & $3.75(1.54,9.17)$ & 0.004 & $1.82(1.26,2.64)$ \\
\hline
\end{tabular}

of this interaction were $p=0.002$ for the sex-and ageadjusted model and $p=0.002$ for fully adjusted model.

To verify the validity of using a sex-combined model in the present study, we also conducted a sex-specific analysis, and found essentially the same associations. Among subjects with lower platelets, the multivariable ORs and $95 \%$ CI of carotid atherosclerosis for 1 SD increments in handgrip strength were $1.20(0.77,1.85)$ for men and $0.47(0.25,0.87)$ for women, while among subjects with higher platelets, the corresponding values were $2.04(1.16,3.58)$ for men and $1.55(0.92,2.62)$ for women.

\section{DISCUSSION}

The major findings of the present study reveal a positive association between handgrip strength and carotid subclinical atherosclerosis among hypertensive subjects with higher, but not lower, platelet counts. These results lead us to speculate that subjects with a beneficial influence on prevention of sarcopenia (maintenance of handgrip strength) may possess the capacity of active endothelial repair that causes atherosclerosis.

Sarcopenia is associated with impairment of capillary function [31]; and microvascular endothelium disruption and impaired blood flow could be exacerbated by common age-related diseases, including hypertension and sarcopenia [1].
Our previous study of Japanese elderly men reported a positive association between circulating CD34-positive cells and handgrip strength in hypertensive subjects [32]. We therefore speculate that vascular maintenance provided by circulating CD34-positive cells is one possible background mechanism behind the positive association between handgrip strength and carotid subclinical atherosclerosis.

Recently, platelets have been revealed to play an important role in vascular culture maintenance together with CD34-positive cells [12-21]. Platelets induce the differentiation of human CD34-positive cells not only into endothelial cells but into foam cells as well [20], which are a well-known contributing factor in the development of atherosclerotic lesions. Previously, we reported that among subjects with hypertension, platelet count is positively associated with CIMT but not with circulating CD34positive cells, since consumptive reduction of circulating CD34-positive cells is induced by aggressive vascular repair [33]. Therefore, among hypertensive subjects, those with a higher platelet count might have higher vascular repair activity than those with lower platelet counts.

Since hematopoietic stem cells, known as CD34positive cells, promote angiogenesis [5], development of atherosclerosis may also indicate vascular culture maintenance activity, including microvascular endothelium repair and collateral blood flow, which plays an important role in providing blood flow to muscles. 
On the other hand, active hematopoietic bone marrow declines with age [26-29], which may result in insufficient vascular endothelium repair in elderly subjects. Since atherosclerosis is a result of aggressive endothelial repair, the existence of atherosclerosis in hypertensive elderly subjects also partly indicates elevated bone marrow activity, which reduces the risk of insufficient vascular endothelium repair and microvascular endothelium disruption. With these mechanisms, handgrip strength should be positively associated with atherosclerosis.

Among elderly hypertensive subjects, while clinical atherosclerosis is known to be associated with blood flow impairment, subclinical atherosclerosis may be associated with comparative active maintenance of muscle blood flow by indicating endothelial repair activity.

In addition to that, since capillary network remodeling such as angiogenesis is essential for the physical adaptation of skeletal muscle to exercise, occurs in response to the mechanical forces of elevated capillary share stress and cell stretch $[34,35]$ the status of maintenance handgrip also should stimulate bone marrow activity.

However, the necessity of endothelial repair, which stimulates bone marrow activity, is determined by the degree of endothelial injury. Subjects with lower levels of endothelial injury might therefore have lower platelet values and a stronger handgrip. Therefore, in subjects with a lower platelet count, no significant positive association between handgrip strength and atherosclerosis would be observed.

Figure 1 shows the possible mechanism underlying the association between handgrip strength and endothelium repair among hypertensive subjects. Higher platelet counts indicate aggressive endothelial repair that results in the development of atherosclerosis, angiogenesis and maintenance of the microvascular endothelium, which is associated with maintaining handgrip strength. And lower platelet counts result in two types of subjects - those who possess sufficient repair capacity and present with less damage to the endothelium, and those with insufficient repair of the endothelium due to the age-related reduction of bone marrow activity. Since hypertension and atherosclerosis have a bidirectional association (vicious cycle) [36], the favorable association between maintaining handgrip strength and formation of atherosclerosis is especially true for subjects with hypertension. The present study found a significant effect on carotid atherosclerosis from handgrip strength and two platelet level categories (high and low), which partly supports the above-mentioned different characteristics on endothelial repair capacity based on platelet levels.

Potential limitations of this study warrant consideration. Although a significant positive association exists between handgrip strength and CIMT, no data was available with regard to the evaluation of endothelial function. Further analyses that include endothelial function-related data such as Flow Mediated Dilation (FMD) will be necessary. And because platelets play an important role in vascular culture maintenance together with CD34-positive cells [12-21], further analyses that include CD34-positive cell data may be informative in clarifying the background mechanisms behind the present results. Additionally, as this was a cross-sectional study, causal relationships were not able to be established.

In conclusion, a positive association exists between handgrip strength and subclinical carotid atherosclerosis among elderly hypertensive subjects with higher, but not lower platelet counts. These results lead us to speculate that subjects with a beneficial influence on prevention of sarcopenia (maintenance of handgrip strength) may possess the capacity of active endothelial repair that causes atherosclerosis.

\section{MATERIALS AND METHODS}

\section{Study population}

The study population comprised 1,803 residents aged 60-89 years from the western rural communities of Goto city who had undergone an annual medical checkup from 2015 to 2016 as recommended by the Japanese government. Subjects without blood pressure data $(n=$ 2 ) were excluded from the analysis. Endothelial repair activity evaluated by circulating CD34-positive cell count may be essential for maintaining handgrip strength in elderly hypertensive subjects [32]. Since platelets play an important role in vascular culture together with CD34positive cells [12-21], and platelet count is positively associated with CIMT in hypertensive subjects but not in non-hypertensive subjects [33], subjects without hypertension were excluded $(n=910)$. An analysis limited to hypertensive subjects should emphasize the impact of atherosclerosis as an indicator of endothelial repair, which relates to maintaining handgrip strength. We defined hypertension according to previous studies that evaluated the impact of platelets and circulating CD34-positive cell count as an indicator of endothelial repair activity [33, 3639], namely, a systolic blood pressure $\geq 140 \mathrm{mmHg}$ and/ or a diastolic blood pressure $\geq 90 \mathrm{mmHg}$. To avoid the influence of undernutrition and paralysis caused by stroke, subjects with low body mass index $\left(\mathrm{BMI} ;<18.5 \mathrm{~kg} / \mathrm{m}^{2}\right)(n$ $=45)$ and history of stroke $(n=42)$ were also excluded from the analysis, as were persons with missing data $(n=6$ for handgrip data and $n=3$ for CIMT data). The remaining participants, comprising 795 subjects (451 men and 344 women) with a mean age of 73.0 years (standard deviation (SD): 7.4; range: 60-89), were enrolled in the study.

This study was approved by the Ethics Committee for Human Use of Nagasaki University (project registration number 14051404). Written consent forms 
were available in Japanese to ensure comprehensive understanding of the study objectives, and informed consent was provided by the participants.

\section{Data collection and laboratory measurements}

Body weight and height were measured with an automatic body composition analyzer (BF-220; Tanita, Tokyo, Japan) and BMI $\left(\mathrm{kg} / \mathrm{m}^{2}\right)$ was calculated. Systolic and diastolic blood pressure were recorded at rest.

Blood samples were collected in an EDTA-2K tube and a siliconized tube. Platelet levels in samples from the EDTA-2K tube were measured at SRL, Inc. (Tokyo, Japan) using an automated procedure.

Triglycerides (TG) and creatinine were each measured enzymatically. HDL-cholesterol (HDL) was measured using the direct method, while hemoglobin A1c $(\mathrm{HbA} 1 \mathrm{c})$ was measured using the latex coagulation method.

Handgrip strength was recorded as the grip strength from 2 measurements performed with each hand using a handgrip dynamometer (Smedley, Matsumiya Ika Seiki Seisakujo, Tokyo, Japan), with the maximum value used.

Measurement of carotid intima media thickness (CIMT) was determined by ultrasonography of the left and right common carotid arteries by an experienced vascular technician using a LOGIQ Book XP with a 10$\mathrm{MHz}$ transducer (GE Healthcare, Milwaukee, WI, USA). Mean and maximum values for the left and right CIMT were calculated using automated digital edge-detection software (Intimascope; MediaCross, Tokyo, Japan) and a protocol that has been described in detail elsewhere [40]. The values of right and left CIMT without measurement of plaque were calculated, and the max CIMT value was used for analysis. Since a previous study reported normal CIMT value as $<1.1 \mathrm{~mm}$, we defined atherosclerosis as CIMT $\geq 1.1 \mathrm{~mm}[41]$.

\section{Statistical analysis}

Characteristics of the study population based on handgrip strength and stratified by platelet levels were expressed as mean \pm standard deviation.

Odds ratios (OR) and 95\% confidence intervals (CI) for carotid atherosclerosis (CIMT $\geq 1.1 \mathrm{~mm}$ ) associated with handgrip strength were calculated with the aid of logistic regression models. In addition, subjects were stratified by platelet levels, since they may act as an indicator of vascular repair activity $[33,36]$.

Two different approaches were used for making adjustments for confounding factors. In the first, we adjusted only for sex-and age. In the second, we included other potential confounding factors, namely, smoking status, alcohol consumption, systolic blood pressure $(\mathrm{mmHg})$, BMI $\left(\mathrm{kg} / \mathrm{m}^{2}\right)$, HDL-cholesterol (mg/dL), TG
(mg/dL) and HbA1c (\%). All statistical analyses were performed with the SAS system for Windows (version 9.3; SAS Inc., Cary, NC), with values of $p<0.05$ regarded as being statistically significant.

\section{ACKNOWLEDGMENTS}

We are grateful to the staff of the Goto city office for their outstanding support.

\section{CONFLICTS OF INTEREST}

The authors declare that they have no competing interests.

\section{FUNDING}

This study was supported by Grants-in-Aids for Scientific Research from the Japan Society for the Promotion of Science (No. 25291107, No.22370090 and No. 15K07243), Kanae Foundation for the Promotion of Medical Sciences, and Meiji Yasuda Life Foundation of Health and Welfare.

\section{REFERENCES}

1. Payne GW. Effect of inflammation on the aging microcirculation: impact on skeletal muscle blood flow control. Microcirculation. 2006; 13:343-52. doi: 10.1080/10739680600618918.

2. Endemann DH, Schiffrin EL. Endothelial dysfunction. J Am Soc Nephrol. 2004; 15:1983-92. doi: 10.1097/01. ASN.0000132474.50966.DA.

3. den Ouden ME, Schuurmans MJ, Arts IE, Grobbee DE, Bots ML, van den Beld AW, Lamberts SW, van der Schouw YT. Atherosclerosis and physical functioning in older men, a longitudinal study. J Nutr Health Aging. 2013; 17:97-104. doi: 10.1007/s12603-012-0424-2.

4. Shioi A, Katagi M, Okuno Y, Mori K, Jono S, Koyama H, Nishizawa Y. Induction of bone-type alkaline phosphatase in human vascular smooth muscle cells: roles of tumor necrosis factor-alpha and oncostatin $\mathrm{M}$ derived from macrophages. Circ Res. 2002; 91:9-16.

5. Takakura N, Watanabe T, Suenobu S, Yamada Y, Noda T, Ito Y, Satake M, Suda T. A role for hematopoietic stem cells in promoting angiogenesis. Cell. 2000; 102:199-209.

6. Yamada Y, Takakura N. Physiological pathway of differentiation of hematopoietic stem cell population into mural cells. J Exp Med. 2006; 203:1055-65. doi: 10.1084/ jem.20050373.

7. Shi Q, Rafii S, Wu MH, Wijelath ES, Yu C, Ishida A, Fujita Y, Kothari S, Mohle R, Sauvage LR, Moore MA, Storb RF, Hammond WP. Evidence for circulating bone marrowderived endothelial cells. Blood. 1998; 92:362-7. 
8. Calvi LM, Adams GB, Weibrecht KW, Weber JM, Olson DP, Knight MC, Martin RP, Schipani E, Divieti P, Bringhurst FR, Milner LA, Kronenberg HM, Scadden DT. Osteoblastic cells regulate the haematopoietic stem cell niche. Nature. 2003; 425:841-6. doi: 10.1038/nature02040.

9. Zhang J, Niu C, Ye L, Huang H, He X, Tong WG, Ross J, Haug J, Johnson T, Feng JQ, Harris S, Wiedemann LM, Mishina Y, Li L. Identification of the haematopoietic stem cell niche and control of the niche size. Nature. 2003; 425:836-41. doi:10.1038/nature02041.

10. Hager S, Lampert FM, Orimo H, Stark GB, Finkenzeller G. Up-regulation of alkaline phosphatase expression in human primary osteoblasts by cocultivation with primary endothelial cells is mediated by p38 mitogen-activated protein kinase-dependent mRNA stabilization. Tissue Eng Part A. 2009; 15:3437-47. doi: 10.1089/ten.TEA. 2009.0133.

11. Sata M, Saiura A, Kunisato A, Tojo A, Okada S, Tokuhisa T, Hirai H, Makuuchi M, Hirata Y, Nagai R. Hematopoietic stem cells differentiate into vascular cells that participate in the pathogenesis of atherosclerosis. Nat Med. 2002; 8:4039. doi:10.1038/nm0402-403.

12. Stellos K, Langer H, Daub K, Schoenberger T, Gauss A, Geisler T, Bigalke B, Mueller I, Schumm M, Schaefer I, Seizer P, Kraemer BF, Siegel-Axel D, et al. Plateletderived stromal cell-derived factor-1 regulates adhesion and promotes differentiation of human CD34+ cells to endothelial progenitor cells. Circulation. 2008; 117:206-15. doi: 10.1161/CIRCULATIONAHA.107.714691.

13. Stellos K, Bigalke B, Langer H, Geisler T, Schad A, Kögel A, Pfaff F, Stakos D, Seizer P, Müller I, Htun P, Lindemann $\mathrm{S}$, Gawaz M. Expression of stromal-cell-derived factor-1 on circulating platelets is increased in patients with acute coronary syndrome and correlates with the number of CD34+ progenitor cells. Eur Heart J. 2009; 30:584-93. doi: 10.1093/eurheartj/ehn566.

14. Seitz G, Boehmler AM, Kanz L, Möhle R. The role of sphingosine 1-phosphate receptors in the trafficking of hematopoietic progenitor cells. Ann N Y Acad Sci. 2005; 1044:84-9. doi: 10.1196/annals.1349.011.

15. Cangiano E, Cavazza C, Campo G, Valgimigli M, Francolini G, Malagutti P, Pratola C, Ferrari R. Different clinical models of CD34+ cells mobilization in patients with cardiovascular disease. J Thromb Thrombolysis. 2011; 32:1-8. doi: 10.1007/s11239-010-0543-8.

16. Golan K, Vagima Y, Ludin A, Itkin T, Cohen-Gur S, Kalinkovich A, Kollet O, Kim C, Schajnovitz A, Ovadya Y, Lapid K, Shivtiel S, Morris AJ, et al. S1P promotes murine progenitor cell egress and mobilization via S1P1-mediated ROS signaling and SDF-1 release. Blood. 2012; 119:247888. doi: 10.1182/blood-2011-06-358614.

17. Zou J, Yuan C, Wu C, Cao C, Yang H. The effects of platelet-rich plasma on the osteogenic induction of bone marrow mesenchymal stem cells. Connect Tissue Res. 2014; 55:304-9. doi: 10.3109/03008207.2014.930140.
18. Matsubara Y, Ono Y, Suzuki H, Arai F, Suda T, Murata M, Ikeda Y. OP9 bone marrow stroma cells differentiate into megakaryocytes and platelets. PLoS One. 2013; 8:e58123. doi: 10.1371/journal.pone.0058123.

19. Gunn N, Damon L, Varosy P, Navarro W, Martin T, Ries C, Linker C. High CD34+ cell dose promotes faster platelet recovery after autologous stem cell transplantation for acute myeloid leukemia. Biol Blood Marrow Transplant. 2003; 9:643-8. doi:10.1016/S1083.

20. Daub K, Langer H, Seizer P, Stellos K, May AE, Goyal P, Bigalke B, Schönberger T, Geisler T, Siegel-Axel D, Oostendorp RA, Lindemann S, Gawaz M. Platelets induce differentiation of human CD34+ progenitor cells into foam cells and endothelial cells. FASEB J. 2006; 20:2559-61. doi: 10.1096/fj.06-6265fje.

21. Majka M, Janowska-Wieczorek A, Ratajczak J, Ehrenman K, Pietrzkowski Z, Kowalska MA, Gewirtz AM, Emerson $\mathrm{SG}$, Ratajczak MZ. Numerous growth factors, cytokines, and chemokines are secreted by human CD34(+) cells, myeloblasts, erythroblasts, and megakaryoblasts and regulate normal hematopoiesis in an autocrine/paracrine manner. Blood. 2001; 97:3075-85..

22. Torsney E, Mandal K, Halliday A, Jahangiri M, Xu Q. Characterisation of progenitor cells in human atherosclerotic vessels. Atherosclerosis. 2007; 191:259-64. doi: 10.1016/j. atherosclerosis.2006.05.033.

23. Moreno PR, Purushothaman KR, Fuster V, Echeverri D, Truszczynska H, Sharma SK, Badimon JJ, O'Connor WN. Plaque neovascularization is increased in ruptured atherosclerotic lesions of human aorta: implications for plaque vulnerability. Circulation. 2004; 110:2032-8. doi:10.1161/01.CIR.0000143233.87854.23.

24. Radziwon-Balicka A, Moncada de la Rosa C, Jurasz P. Platelet-associated angiogenesis regulating factors: a pharmacological perspective. Can J Physiol Pharmacol. 2012; 90:679-88. doi: 10.1139/y2012-036.

25. Mammoto T, Jiang A, Jiang E, Mammoto A. Platelet rich plasma extract promotes angiogenesis through the angiopoietin1-Tie2 pathway. Microvasc Res. 2013; 89:1524. doi: 10.1016/j.mvr.2013.04.008.

26. Brusnahan SK, McGuire TR, Jackson JD, Lane JT, Garvin KL, O'Kane BJ, Berger AM, Tuljapurkar SR, Kessinger MA, Sharp JG. Human blood and marrow side population stem cell and Stro-1 positive bone marrow stromal cell numbers decline with age, with an increase in quality of surviving stem cells: correlation with cytokines. Mech Ageing Dev. 2010; 131:718-22. doi: 10.1016/j. $\operatorname{mad} .2010 .10 .002$.

27. Garvin K, Feschuk C, Sharp JG, Berger A. Does the number or quality of pluripotent bone marrow stem cells decrease with age? Clin Orthop Relat Res. 2007; 465:202-7. doi: 10.1097/BLO.0b013e318159a9b8.

28. Guralnik JM, Ershler WB, Schrier SL, Picozzi VJ. Anemia in the elderly: a public health crisis in hematology. Hematology Am Soc Hematol Educ Program. 2005:528- 
32. doi:10.1182/asheducation-2005.1.528.

29. Cooper B. The origins of bone marrow as the seedbed of our blood: from antiquity to the time of Osler. Proc (Bayl Univ Med Cent). 2011; 24:115-8.

30. Fried LP, Tangen CM, Walston J, Newman AB, Hirsch C, Gottdiener J, Seeman T, Tracy R, Kop WJ, Burke G, McBurnie MA, Cardiovascular Health Study Collaborative Research Group. Frailty in older adults: evidence for a phenotype. J Gerontol A Biol Sci Med Sci. 2001; 56:14656.

31. Wang H, Listrat A, Meunier B, Gueugneau M, CoudyGandilhon C, Combaret L, Taillandier D, Polge C, Attaix D, Lethias C, Lee K, Goh KL, Béchet D. Apoptosis in capillary endothelial cells in ageing skeletal muscle. Aging Cell. 2014; 13:254-62. doi: 10.1111/acel.12169.

32. Yamanashi H, Shimizu Y, Koyamatsu J, Nagayoshi M, Kadota K, Tamai M, Maeda T. Circulating CD34-positive cells are associated with handgrip strength in Japanese older men: The Nagasaki Islands study. J Frailty Aging. 2017; 6:6-11. doi: 10.14283/jfa.2016.107.

33. Shimizu Y, Sato S, Koyamatsu J, Yamanashi H, Nagayoshi M, Kadota K, Maeda T. Platelets as an indicator of vascular repair in elderly Japanese men. Oncotarget. 2016; 7:4491926. doi: 10.18632/oncotarget.10229.

34. Prior BM, Yang HT, Terjung RL. What makes vessels grow with exercise training? J Appl Physiol (1985). 2004; 97:1119-28. doi:10.1152/japplphysiol.00035.2004.

35. Hudetz AG, Kiani MF. The role of wall shear stress in microvascular network adaptation. Adv Exp Med Biol. 1992; 316:31-9.

36. Shimizu Y, Sato S, Koyamatsu J, Yamanashi H, Nagayoshi M, Kadota K, Kawashiri SY, Inoue K, Nagata Y, Maeda T. Platelets and circulating CD34-poositive cells as an indicator of the activity of the vicious cycle between hypertension and endothelial dysfunction in elderly Japanese men. Atherosclerosis. 2017; 259:26-31. doi: 10.1016/j.atherosclerosis.2017.02.016.
37. Shimizu Y, Sato S, Koyamatsu J, Yamanashi H, Nagayoshi M, Kadota K, Maeda T. Circulating CD34-positive cells, glomerular filtration rate and triglycerides in relation to hypertension. Atherosclerosis. 2015; 243:71-6. doi: 10.1016/j.atherosclerosis.2015.08.035.

38. Shimizu Y, Sato S, Koyamatsu J, Yamanashi H, Nagayoshi M, Kadota K, Maeda T. Height is an indicator of vascular maintenance capacity in older men. Geriatr Gerontol Int. 2016 Aug 26. doi: 10.1111/ggi.12876. [Epub ahead of print].

39. Shimizu Y, Sato S, Koyamatsu J, Yamanashi H, Nagayoshi M, Kadota K, Kawashiri SY, Maeda T. Possible mechanism underlying the association between higher hemoglobin level and hypertension in older Japanese men. Geriatr Gerontol Int. 2017 June 5. doi: 10.1111/ggi.13068. [Epub ahead of print].

40. Hara T, Takamura N, Akashi S, Nakazato M, Maeda T, Wada M, Nakashima K, Abe Y, Kusano Y, Aoyagi K. Evaluation of clinical markers of atherosclerosis in young and elderly Japanese adults. Clin Chem Lab Med. 2006; 44:824-9. doi:10.1515/CCLM.2006.149.

41. Kawamori R, Yamasaki Y, Matsushima H, Nishizawa H, Nao K, Hougaku H, Maeda H, Handa N, Matsumoto M, Kamada T. Prevalence of carotid atherosclerosis in diabetic patients. Ultrasound high-resolution B-mode imaging on carotid arteries. Diabetes Care. 1992; 15:1290-4. 